\title{
Diabetes, Hypertension, Arthritis and other Chronic Non- communicable Diseases in an English-Speaking Caribbean Nation: A Health Perspective
}

\author{
Paul Andrew Bourne ${ }^{1 *}$, Cynthia Francis ${ }^{2}$, Charlene Sharpe-Pryce ${ }^{3}$, Angela Hudson Davis ${ }^{4}$ and Ikhalfani \\ Solan $^{5}$ \\ ${ }^{1}$ Socio-Medical Research Institute, Jamaica \\ ${ }^{2}$ University of Technology, Jamaica \\ ${ }^{3}$ Chair, Department of History, Northern Caribbean University, Mandeville, Jamaica \\ ${ }^{4}$ Capella University, Capella Tower, 225 South Sixth Street, 9th Fl., Minneapolis, MN 55402, USA \\ ${ }^{5}$ Department of Mathematics and Computer Science, South Carolina State University, USA
}

Received: January 02, 2014; Accepted: February 06, 2014; Published: February 08, 2014

*Corresponding author: Paul Andrew Bourne, Socio-Medical Research Institute, 66 Long Wall Drive, Stony Hill PO, Kingston 9, Kingston, Jamaica, Tel: 1-876-566-3088; E-mail: paulbourne1@yahoo.com

\begin{abstract}
Introduction: Four (4) in every five (5) people in the developing world die from chronic non-communicable diseases (NCDs); yet the literature has few studies on the health status of those with these conditions. This study fills the gap in the literature.

Objectives: These are to disaggregate particular NCDs and provide detailed socio-demographic characteristics on those conditions, evaluate certain chronic illnesses by health indicators, examine the combinations of particular chronic conditions, and determine social determinants of health for those with particular chronic health conditions.
\end{abstract}

Methods: The Jamaica Survey of Living Conditions which is used for this work is a modification of the World Bank's Households Living Standard Survey. It is an annual and nationally representative crosssectional probability survey. This study utilizes 619 respondents who report having NCDs.

Results: The majority of the respondents have Other NCDs $(37.8 \%)$ followed by hypertension $(33.3 \%)$, diabetes $(19.9 \%)$ and arthritis $(9.0 \%)$. Fifty-five $(55 \%)$ percent of respondents reside in rural areas; $42.7 \%$ are single ; $46.4 \%$ are elderly; $9.2 \%$ are children; $3.5 \%$ have at least secondary level education, $42.5 \%$ are wealthy compared to $37.8 \%$ who are poor and $65.3 \%$ are females. Seventyone $(71 \%)$ percent of those with diabetes have hypertension; $90.2 \%$ of those who report having hypertension have diabetes; $87.1 \%$ of those who indicate having arthritis have hypertension and $68.2 \%$ of respondents who indicate having other NCDs have hypertension.

Conclusion: The current findings unearth pertinent information that are critical in helping to formulate new policies and intervention programmes to tackle the NCDs epidemic.

Keywords: Arthritis; Cardiovascular disease; Coronary arterty disease; Diabetes; Hypertension; Health; Morbidity; Mortality; Noncommunicable disease; Social determinants

\section{Introduction}

It is well established in demography and health literature that there is a statistical association between morbidity and mortality, mortality and life expectancy, morbidity and health status, and morbidity and life expectancy. Since the $20^{\text {th }}$ century, health status of people in the world has significantly increased because of the transition from infectious to chronic non-communicables diseases (NCDs) [1], which is also an explanation for the increases in life expectancy. During the last 100 years, morbidities that have accounted for the majority of human deaths, particularly in developing countries, are NCDs such as diabetes, cardiovascular diseases, chronic respiratory diseases, ischaemic heart diseases, neoplasms and lung diseases [1]. Currently these are the singly leading cause of human deaths throughout the globe, which for centuries have played second fiddle to infectious diseases such as small pox, bubonic plague, pneumonia, diarrhea and enteritis, and tuberclosis. In 2005, the World Health Organization [1] indicates that annually there are 35 million human deaths to NCDs which is twice the number of deaths by total infectious diseases and that 51.4 percent of the aggregate NCDs are females. Enveloped in the aforementioned statistics are the present reality of people in the world, the human face of NCDs, the health burden of these conditions on families as well as the society and the epidemiological transition that has occurred in our world, especially since 1900 in developed nations and later in developing countries.

The World Health Organization (WHO) [1] has empirically established that four-fifths of people who have chronic illnesses are in the developing nations and that NCDs account for 60 percent of global mortalities. Other studies have concurred with the relationship between illness, especially chronic conditions, and poverty as well as morbidity and mortality [2,3]. The 
burden of NCDs in the world has changed and there is transition in time, societies and typology of diseases. There has been an epidemiological transition in the Caribbean which began since the 1940s. During the 1940s, infectious diseases such as tuberculosis, nephritis, syphilis, pneumonia and influenza were the leading causes of mortality in the region and these shifted in the 1990s to NCDs such as malignant neoplasm, diabetes mellitus, ischaemic heart disease, other heart disease and hypertension. Unlike in the Caribbean, the epidemiological transition began in United States in the 1900s [4], which have seen dramatic changes in disease typologies. It can be extrapolated from the work of the WHO as well as other research that chronic non-communicable diseases are 'silent killers' and that these are public health challenges for many governments in the developing world.

In Jamaica, like in other English-speaking Caribbean islands, over the last decade, there has been a high frequency of media reports on violent crimes; although the 'silent killers' are singly the commonest cause of mortality and outweigh the prevalence of deaths by major crimes (murder, rape, robbery, carnal abuse, shooting, larceny and break-ins). In fact, the burden of NCDs in the Caribbean Community (CARICOM) is the highest in the Latin America and the Caribbean, which offers an insights into the health challenges in the region. Hospedales et al. [4] opine that among peoples in the English-speaking Caribbean nations, the rate of NCDs is higher than in the Americas. Furthermore, statistics reveal that there is an increase in chronic diseases as well as mortality by way of neoplasms, diabetes and hypertension in the Caribbean [4-8]; yet there are few works on the health status of those with chronic conditions [9-13]. A Caribbean scholar (Rainford Wilks) writes about the rise of hypertension in the $21^{\text {st }}$ Century this way when he surmises that "The importance of this,silent killer, hypertension to morbidity and mortality is even more obvious today with the sharp reduction in the diseases associated with infection and under-nutrition"[14], which highlights the new risk factors and poor behavioral practices of peoples in the developing world.

Other Caribbean scholars (Professor Errol Y. St. A Morrison and Dr. J. Callender) have expanded on the discourse of a single 'silent killer' to multimorbidity ( $\geq 2$ chronic conditions). Morrison [6] writes that diabetes and hypertension are twin problems in the Caribbean, suggesting the combinations of chronic conditions among patients and the expanded burden of this reality. Callender [5] further notes that fifty (50\%) percent of Caribbean nationals with hypertension have diabetes, making the discourse of NCDs a multiple phenomenon and added on the non-demonination of Morrison's perspective. The reality is, there is at least a twin burden of chronic conditions experienced by many people as rarely an individual has only one non-communicable disease. According to Wilks [14], hypertension is associated with other health conditions such as coronary heart disease, chronic renal disease, left ventricular hypertrophy, heart failure, peripheral vascular disease, and many of those are among the ten leading causes of death in the developing world. Historically, the West Indies did not have a single case of diabetes up to 1798 and by 1868 there were many reported cases among the indentured
Indian labourers and this extends to other cardiovascular diseases [15].

The discourse on chronic conditions cannot cease with comorbidities and a historical perspective on the matter as Morrison [16] introduces others tenets to the 'silent killers'. He notes that diabetes mellitus accounts for the most absenteeism, new cases of blindness, amputations and coronary diseases in Jamaica. The issue of coronary artery diseases as 'silent killer' extends beyond the Caribbean. According to Tilluckdharry [17] approximately 12 million deaths are caused by cardiovasular diseases in the world and 1 in every 2 deaths in the developed nations is as a result of these diseases, which is also the case in the developing countries. The perspectives on chronic noncommunicable conditions now extend from other illnesses to production and productivity as well as international coverage. Although Morrison does not use the terminology quality of life in this article when he forwards the coverage of diabetes mellitus, clearly it is embedded therein. With the high rate of mortality among those with chronic non-communicable conditions in the developing world, especially Jamaica, there is no denial that the healthy life expectancy of those with chronic conditions must be lower than for those without functional disabilities. In fact, the World Health Organization (WHO) has reduced life expectancy by at least six years in the developing world, nine years for Jamaicans, to account for time living with health conditions such as diabetes, hypertension, heart diseases, among others [18] in order to adjust life expectancy. According to the WHO:

Disability Adjusted Life Expectancy (DALE) summarizes the expected number of years to be lived in what might be termed the equivalent of "full health." To calculate DALE, the years of ill health are weighted according to severity and subtracted from the expected overall life expectancy to give the equivalent years of healthy life [18].

The World Health Organization has worked assiduously to develop and launch particular perspectives on health, and cardiovascular diseases are responsible for the development of DALE because they reduce functional ability. Prior to the slant taken by WHO on health, the conceptualization of this variable was focused on a particular physiological state of the individual. However, with the introduction of new operational definition of the construct since the later 1940s by the WHO, health has been expanded to mean much more than the absence of diseases (physiological state), which must also include measures of healthy life expectancy, happiness, utility, personal preference, and self-reported quality of life. With this extension of population health, new genres of studies are commissioned and done in the area of health research. Despite the expanded definition of health and the realism that there is a self-rated health aspect to chronic non-communicable diseases, studies on health status of those who have particular chronic conditions (diabetes, hypertension, arthritis and other chronic illnesses) have not comprehensively examined many of the health indicators including social determinants [19]. The studies on the health indicators of those with particular chronic conditions have been on elderly [10]; insured and uninsured [11]; males [12]; hypertensive 
[13], and the one which has examined patients with chronic recurring diseases stop short of examining the various health indicators and factors that account for good health status [9]. The objectives of this study, therefore, are to disaggregate particular chronic non-communicable conditions and provide detailed socio-demographic characteristics on those illnesses, evaluate certain chronic illnesses by way health indicators, examine the combinations of certain chronic conditions, and determine social determinants of health for those with the chronic health conditions.

\section{Methods and Materials}

The Jamaica Survey of Living Conditions (JSLC) is an annual survey that is jointly conducted by the Planning Institute of Jamaica (PIOJ) and the Statistical Institute of Jamaica (STATIN). It is a nationally representative cross-sectional descriptive surveys drawn using stratified random sampling techniques. The JSLC collects data on households' characteristics, health, education, expenditure, social programmes, and other information. Each year, a special unit is added that examines a particular issue. The example here is in 2002, the special unit was crime and victimization. The survey is collected using a standardized instrument (ie. questionnaire) that on average takes approximately 45 minutes to complete by each respondent. The JSLC is modelled from the World Bank's Living Standards Measurement Study (LSMS) household survey [20]. There are some modifications to the LSMS, as JSLC is more focused on policy impacts and therefore this is reflected in the collected data.

The JSLC is published in a document of the same title [20]. According to the JSLC [20], the sample is weighted to reflect the population of Jamaica. The households in the JSLC are interviewed on an annual basis for a period of up to four years, after which a new representative sampling frame is redesign and drawn. A detailed presentation of the sampling techniques are in other published works [9-13,21,22]. The data are entered, stored and retrieved in the Statistical Packages for the Social Sciences (SPSS) for Windows, Version 21.0. For this study, descriptive statistics are performed for the socio-demographic characteristics of the sample; the bivariate analyses are chi-square and analysis of variance (ANOVA), and multivariate analysis (binary logistic regression) is used to establish factors that influence binary dependent variable (good self-rated health status).

\section{Definition of variables}

Health: This is defined as the self-rated health status of an individual [23].

Good health: Is a binary variable where $1=$ at least good selfrated health status and $0=$ otherwise.

Age: This is the total number of years lived since birth, measured from one birthday to the next [23].

Health-care Seeking Behavior (or visits to medical professional): This is derived from the question 'Have you sought medical attention in the last four weeks (using the survey period), where $1=y e s$ and $0=$ otherwise.
Age groups: Children are individuals ages 0 to 15 years old; young adults, 16-30 years; other aged adults, 31-59 years old; young old, 60-74 years old; old old, 75-84 years old and oldest old, 85+ years old.

Other NCDs: These include malignant neoplasms, ischaemic and other heart diseases, and high cholesterol.

Health Insurance Coverage: This is a binary measure, in which 1 denotes self-reported ownership of private and/or public health insurance coverage and 0 is otherwise.

Length of illness: The number of days an individual report that he(she) experiences ill-health due to NCDs.

Purchased prescribed medications: This is an individual reporting that he(she) filled the prescription that he(she) received on visit to the health care practitioner(s).

\section{Results}

Table 1 summarizes the socio-demographic characteristics of the sampled population. The sampled population is 619 respondents. Of the sampled respondents, $65.3 \%$ are females, $46.3 \%$ are elderly, $9.2 \%$ are children, $38.2 \%$ are married, $42.7 \%$ are single, $55.3 \%$ dwell in rural areas, and $37.8 \%$ are poor with $21.0 \%$ being below the poverty line. Only $3.5 \%$ of the respondents have at least secondary education (secondary, 2.7\%; tertiary, $0.8 \%$ ) and $27.5 \%$ are holders of a health insurance policy. Of those who are holders of a health insurance policy $(27.5 \%)$, 17.0\% hold a public one (Jamaica Drug for the Elderly, National Health Fund).

Table 2 presents information on chronic health conditions (diabetes, hypertension, arthritis, and other) by selected socio-demographic characteristics (age, marital status, area of residence, income quintile, and gender). The sampled respondents comprise of $19.9 \%$ of people who reported having diabetes, 33.3\% with hypertension, 9.0\% with arthritis and $37.8 \%$ with other chronic conditions. None of the children in this study have hypertension and arthritis; but, $2.4 \%$ have diabetes and $23.1 \%$ have other chronic health conditions. Diabetes, hypertension and arthritis are mostly associated with elderly respondents, $59.3 \%, 60.2 \%$ and $67.9 \%$ respectively $(\chi 2=24.740$, $P<0.0001)$. The majority of those with diabetes $(74.8 \%)$ and hypertension $(71.8 \%)$ are females with marginally more females than males having arthritis and other chronic health conditions $(\chi 2=18.587, P<0.0001)$. At least two-fifths of respondents with diabetes, hypertension and arthritis are married people $(\chi 2=53.023, P<0.0001)$. Fifty-four (54\%) percent of those in the wealthy income group in the sample have diabetes compare to $33.4 \%$ of those in poor income category; the percentages of poor and wealthy respondents who have hypertension are 39.8 and 36.8 respectively $(\chi 2=13.205, P=0.354)$. At least one half of those with diabetes, hypertension, arthritis and other chronic health conditions reside in rural areas, $52.0 \%, 57.3 \%, 53.6 \%$, and $55.6 \%$ respectively $(\chi 2=7.027, P=0.318)$.

Table 3 illustrates information relating to chronic health conditions disaggregated by selected health indicators (health 
care utilization, health insurance coverage, health-care seeking behavior, health status, length of illness and medical expenditure). There is no statistical association between health care utilization and typology of chronic health conditions $(\chi 2=1.855, P=0.603)$, with at least three-fourth $(3 / 4)$ of the respondents utilizing private health care facilities. Similarly, no statistical difference emerge between 1) length of illness and typology of chronic health conditions (F-statistic $=1.114, P=0.287$ ); 2 ) number of visitations to health practitioner and typology of chronic health conditions (F-statistic $=1.640, P=0.179) ; 3$ ) medical expenditure and typology of chronic health conditions (F-statistic $=0.845, P=$ 0.470 ). However, statistical relationship exists between typology of chronic conditions and 1$)$ health-care seeking behaviour $(\chi 2=$ 12.157, $\mathrm{P}=0.007) ; 2$ ) health insurance ownership ( $\chi 2=12.157, P$ $<0.0001)$; and 3 ) self-rated health status $(\chi 2=22.721, P<0.0001)$. Furthermore, people who have diabetes mellitus are more likely

Table 1: Sociodemographic Characteristics of sampled respondents, $n$ $=619$.

\begin{tabular}{|c|c|}
\hline Characteristic & n (\%) \\
\hline \multicolumn{2}{|l|}{ Sex } \\
\hline Male & $215(34.7)$ \\
\hline Female & $404(65.3)$ \\
\hline \multicolumn{2}{|l|}{ Educational attainment } \\
\hline No formal & $549(88.7)$ \\
\hline Primary & $48(7.8)$ \\
\hline Secondary & $17(2.7)$ \\
\hline Tertiary & $5(0.8)$ \\
\hline \multicolumn{2}{|l|}{ Age group } \\
\hline Children & $57(9.2)$ \\
\hline Young adults & $53(8.6)$ \\
\hline Other aged adults & $222(35.9)$ \\
\hline Young Old & $164(26.5)$ \\
\hline Old Old & $95(15.3)$ \\
\hline Oldest Old & $28(4.5)$ \\
\hline \multicolumn{2}{|l|}{ Area of residence } \\
\hline Urban zones & $167(27.0)$ \\
\hline Peri-urban areas & $110(17.8)$ \\
\hline Rural areas & $342(55.3)$ \\
\hline \multicolumn{2}{|l|}{ Marital Status } \\
\hline Married & $214(38.2)$ \\
\hline Single & $239(42.7)$ \\
\hline Divorced & $17(3.0)$ \\
\hline Separated & $10(1.8)$ \\
\hline Widowed & 80 (14.3) \\
\hline \multicolumn{2}{|l|}{ Income Quintile } \\
\hline 1 (below poverty line) & $130(21.0)$ \\
\hline 2 (poor) & $104(16.8)$ \\
\hline 3 (middle) & $122(19.7)$ \\
\hline 4 (wealthy) & $132(21.3)$ \\
\hline 5 (wealthiest 20\%) & $131(21.2)$ \\
\hline \multicolumn{2}{|c|}{ Health Insurance Coverage } \\
\hline Yes & $170(27.5)$ \\
\hline No & $448(72.5)$ \\
\hline Head of household & $344(55.6)$ \\
\hline
\end{tabular}

Table 2: Chronic Health conditions disaggregated by Age group, Marital status and Area of Residence, Income Quintile and Gender, $\mathrm{n}=619$.

\begin{tabular}{|c|c|c|c|c|}
\hline Characteristic & Diabetes & $\begin{array}{c}\text { Hyperten- } \\
\text { sion }\end{array}$ & Arthritis & $\begin{array}{c}\text { Other } \\
\text { Chronic }\end{array}$ \\
\hline Age group & $\mathrm{n}(\%)$ & $\mathrm{n}(\%)$ & $\mathrm{n}(\%)$ & $\mathrm{n}(\%)$ \\
\hline Children & $3(2.4)$ & $0(0.0)$ & $0(0.0)$ & $54(23.1)$ \\
\hline Young adults & $3(2.4)$ & $6(2.9)$ & $1(1.8)$ & $43(18.4)$ \\
\hline Other aged adults & $44(35.8)$ & $76(36.9)$ & $17(30.4)$ & $85(36.3)$ \\
\hline Young Old & $49(39.8)$ & $61(29.6)$ & $22(39.3)$ & $32(13.7)$ \\
\hline Old Old & $19(15.4)$ & $49(23.8)$ & $14(25.0)$ & $13(5.6)$ \\
\hline Oldest Old & $5(4.1)$ & $14(6.8)$ & $2(3.6)$ & $7(3.0)$ \\
\hline Marital status & & & & \\
\hline Married & $48(40.0)$ & $91(44.4)$ & $24(42.9)$ & $51(28.5)$ \\
\hline Single & $39(32.5)$ & $69(33.7)$ & $22(39.3)$ & $109(60.9)$ \\
\hline Divorced & $10(8.3)$ & $3(1.5)$ & $1(1.8)$ & $3(1.7)$ \\
\hline Separated & $4(3.3)$ & $5(2.4)$ & $1(1.8)$ & $0(0.0)$ \\
\hline Widowed & $19(15.8)$ & $37(18.0)$ & $8(14.3)$ & $16(8.9)$ \\
\hline Area of Residence & & & & \\
\hline Urban zones & $32(26.0)$ & $47(22.8)$ & $16(28.6)$ & $72(30.8)$ \\
\hline Peri-urban areas & $27(22.0)$ & $41(19.9)$ & $10(17.9)$ & $32(13.7)$ \\
\hline Rural areas & $64(52.0)$ & $118(57.3)$ & $30(53.6)$ & $130(55.6)$ \\
\hline Income Quintile & & & & \\
\hline 1 (below the poverty & $21(17.1)$ & $47(22.8)$ & $15(26.8)$ & $47(20.1)$ \\
\hline line) & $20(16.3)$ & $35(17.0)$ & $10(17.9)$ & $39(16.7)$ \\
\hline 2 (poor) & $16(13.0)$ & $48(23.3)$ & $12(21.4)$ & $46(19.7)$ \\
\hline 3 (middle) & $33(26.8)$ & $38(18.4)$ & $8(14.3)$ & $53(22.6)$ \\
\hline 4 (wealthy) & $33(26.8)$ & $38(18.4)$ & $11(19.6)$ & $49(20.9)$ \\
\hline 5 (wealthiest 20\%) & & & & \\
\hline Gender & $\mathbf{1 2 3 ( 1 9 . 9 )}$ & $\mathbf{2 0 6 ( 3 3 . 3 )}$ & $\mathbf{5 6}(\mathbf{9 . 0})$ & $\mathbf{2 3 4 ( 3 7 . 8 )}$ \\
\hline Male & $31(25.2)$ & $58(28.2)$ & $24(42.9)$ & $102(43.6)$ \\
\hline Female & $92(74.8)$ & $148(71.8)$ & $32(57.1)$ & $132(56.4)$ \\
\hline Total & & & \\
\hline
\end{tabular}

to purchase prescribed medication (73.3\%) than those who have hypertension (70.2\%), arthritis (57.1\%) and those with other chronic conditions (70.6\%). In addition to the aforementioned issues, respondents who indicate having diabetes are more likely to seeking medical care $(72.4 \%)$ than those with hypertension (68.6\%) and arthritis (51.8\%).

Table 4 examines a cross tabulation between the typology of self-reported chronic comorbidities. Seventy-one percent of respondents who have diabetes also have hypertension; $90.2 \%$ of those with hypertension have diabetes; $87.0 \%$ of those with arthritis have hypertension, and $68.2 \%$ of those with other chronic conditions have hypertension. Thirty-eight and two tenths percent of the sample report at least 2 conditions (multimorbidity).

Table 5 presents information on income quintile by selected health indicators. No statistical associates betweeen income 
Table 3: Chronic Health conditions disaggregated by Health care Utilization, Health Insurance Coverage, Health-care seeking behavior, Self-rated health status, Lenth of Illness, and Medical Expenditure, $\mathrm{n}=619$.

\begin{tabular}{|c|c|c|c|c|}
\hline Characteristic & Diabetes & Hypertension & Arthritis & Other Chronic \\
\hline Health Care Utilization & $\mathrm{n}(\%)$ & $\mathrm{n}(\%)$ & $\mathrm{n}(\%)$ & $\mathrm{n}(\%)$ \\
\hline Private & $41(89.1)$ & $54(81.8)$ & $9(75.0)$ & $81(82.7)$ \\
\hline Public & $5(10.5)$ & $12(18.2)$ & $3(25.0)$ & $17(17.3)$ \\
\hline \multicolumn{5}{|l|}{ Health Insurance Coverage } \\
\hline No & $69(56.1)$ & $148(71.8)$ & $41(74.5)$ & $190(81.2)$ \\
\hline Yes & $54(43.9)$ & $58(28.2)$ & $14(25.5)$ & $44(18.8)$ \\
\hline \multicolumn{5}{|l|}{ Health care Seeking Behavior } \\
\hline No & $34(27.2)$ & $64(31.4)$ & $27(48.2)$ & $58(25.0)$ \\
\hline Yes & $89(72.4)$ & $140(68.6)$ & $29(51.8)$ & $174(75.0)$ \\
\hline \multicolumn{5}{|l|}{ Self-rated Health Status } \\
\hline Good & $26(21.1)$ & $55(26.7)$ & $13(23.2)$ & $95(40.9)$ \\
\hline Fair & $67(54.5)$ & $91(44.2)$ & $25(44.6)$ & $83(35.8)$ \\
\hline Poor & $30(24.4)$ & $60(29.1)$ & $18(32.1)$ & $54(23.3)$ \\
\hline \multicolumn{5}{|l|}{ Purchased prescribed medications } \\
\hline No & $31(26.7)$ & $59(29.8)$ & $24(42.9)$ & $67(29.4)$ \\
\hline Yes & $85(73.3)$ & $139(70.2)$ & $32(57.1)$ & $161(70.6)$ \\
\hline Visit/s to medical practitioner & $1.3 \pm 1.5$ & $1.3 \pm 0.7$ & $1.7 \pm 0.8$ & $1.5 \pm 1.3$ \\
\hline Length of Illness & $2.6 \pm 1.7$ & $2.5 \pm 1.9$ & $2.6 \pm 1.8$ & $2.2 \pm 1.4$ \\
\hline Medical Expenditure $^{1}$ & $16.25 \pm 41.67$ & $20.00 \pm 56.93$ & $28.26 \pm 31.09$ & $24.20 \pm 39.89$ \\
\hline
\end{tabular}

${ }^{1}$ Figure are quoted in USD. Where 1 USD = Ja. $\$ 69.06$

Table 4: Comorbidities, $\mathrm{n}=619$.

\begin{tabular}{|c|c|c|c|c|}
\hline Characteristic & Diabetes & Hypertension & Arthritis & Other Chronic \\
\hline & $\%$ & $\%$ & $\%$ & $\%$ \\
\hline Diabetes & - & 90.2 & 6.5 & 68.2 \\
\hline Hypertension & 71.4 & - & - & 18.2 \\
\hline Orthritis & 14.3 & 9.8 & 6.5 & - \\
\hline Total (n) & 14.3 & & $\mathbf{5 6}$ & $\mathbf{2 3 4}$ \\
\hline
\end{tabular}

quintile and 1 ) health status $(\chi 2=9.0, P=0.342), 2)$ typology of chronic conditions $(\chi 2=13.205, P=0.354), 3)$ purchased prescribed medications $(\chi 2=2.875, P=0.579)$, and 4) health care utilization $(\chi 2=4.323, P=0.364)$ as well as no statistical difference between income quintile and medical expenditure (F-statistic $=2.371, P=0.051$, as well as 1$)$ visitation and income quintile (F-statistic $=1.833, P=0.122)$, and income quintile and length of illness (F-statistic $=2.030, P=0.090$ ). However, statistical relationship exists between 1) health insurance coverage and income quintile $(\chi 2=43.499, P<0.0001)$, and 2$)$ health-care seeking behavior and income quintile $(\chi 2=23.753$, $P<0.0001)$.

Table 6 presents variables that illustrate (or not) at least good health status. Of the twelve variables entered in the general health model, only two emerge as factors, age and length of illness. The two variables account for $22.4 \%$ of the variability in good health status, with both variables being negatively correlated with good health status.

\section{Discussion}

The definition of health is such that it includes the absence of illness and general well-being implying that diseases reduce the quality of life of an individual. Tilluckdharry's perspective supports the inverse relationship between illness and wellbeing when he opines that while many cardiovascular diseases may not be fatal, they are debilitating and decrease functional ability [17]. It follows here that cardiovascular diseases reduce health in two ways functionality, and production. The argument for a health perspective for those who have diabetes, hypertension, arthritis and other NCDs is critical to the health discourse because of the likely results of these conditions. According to Tilluckdharry, “... management of cardiovascular diseases is expensive and taxes medical and economic resources considerably" [17], which highlights other rationales for their inclusion in health research. When one considers Tilluckdharry's perspective within the context of their coverage in the world as well as the Caribbean $[17,24]$, it would be fitting and valuable to examine various health indicators of those with diabetes, hypertension, arthritis and other NCDs.

A study by Wilks and colleagues [7] reveal that 57.2 percent of Jamaicans between the ages of 15 and 74 years are at least satisfied with life and with other studies showing that physical health of those with cardiovascular diseases is lower than those without them, a health study is timely. This study answers a number of questions from a health perspective and offers insights to those with particular NCDs, which provide a platform 
Table 5: Income quintile by selected health indicators, $\mathrm{n}=619$.

\begin{tabular}{|c|c|c|c|c|c|}
\hline \multirow{2}{*}{ Characteristic } & \multicolumn{5}{|c|}{ Income Quintile } \\
\hline & 1 & 2 & 3 & 4 & 5 \\
\hline Health Care Utilization & n (\%) & n (\%) & n (\%) & $\mathrm{n}(\%)$ & \\
\hline Private & $46(92.0)$ & $35(85.4)$ & $44(80.0)$ & $38(79.2)$ & $22(78.6)$ \\
\hline Public & $4(8.0)$ & $6(14.6)$ & $11(20.0)$ & $10(20.8)$ & $37(16.7)$ \\
\hline \multicolumn{6}{|l|}{ Health Insurance Coverage } \\
\hline Yes & $18(13.8)$ & $24(23.1)$ & $26(21.5)$ & $39(29.5)$ & $63(48.1)$ \\
\hline No & $112(86.2)$ & $80(76.9)$ & $95(78.5)$ & $93(70.5)$ & $68(51.9)$ \\
\hline \multicolumn{6}{|l|}{ Health Care Seeking Behavior } \\
\hline Yes & $68(53.1)$ & $74(71.2)$ & $93(76.9)$ & $97(74.0)$ & $100(76.3)$ \\
\hline No & $60(46.9)$ & $30(28.8)$ & $28(23.1)$ & $34(26.0)$ & $31(23.7)$ \\
\hline \multicolumn{6}{|l|}{ Self-rated Health Status } \\
\hline Good & 37 (28.7) & $29(27.9)$ & $34(28.1)$ & $44(33.3)$ & $45(34.4)$ \\
\hline Fair & $51(39.5)$ & $48(46.2)$ & $49(40.5)$ & $56(42.4)$ & $62(47.3)$ \\
\hline Poor & $41(31.8)$ & $27(26.0)$ & $38(31.4)$ & $32(24.2)$ & $24(18.3)$ \\
\hline \multicolumn{6}{|l|}{ Purchased prescribed medications } \\
\hline No & $80(62.5)$ & $59(59.6)$ & $68(56.7)$ & 75 (57.3) & $66(52.4)$ \\
\hline Yes & $48(37.5)$ & $40(40.4)$ & $52(43.3)$ & $56(42.7)$ & $60(47.6)$ \\
\hline \multicolumn{6}{|l|}{ Chronic diseases } \\
\hline Diabetes & $21(16.2)$ & $20(19.2)$ & $16(13.1)$ & $33(25.0)$ & $33(25.2)$ \\
\hline Hypertension & $47(36.2)$ & $35(33.7)$ & $48(39.3)$ & $38(28.8)$ & $38(29.0)$ \\
\hline Arthritis & $15(11.2)$ & $10(9.6)$ & $12(9.8)$ & $8(6.1)$ & $11(8.4)$ \\
\hline Other & $47(36.2)$ & $39(37.5)$ & $46(37.7)$ & $53(40.2)$ & $49(37.4)$ \\
\hline Visit/s to medical practitioner (in days) & $1.1 \quad 0.5$ & $1.4 \pm 0.7$ & $1.7 \pm 1.6$ & $1.5 \pm 0.9$ & $1.4 \pm 1.4$ \\
\hline Length of Illness (indays) & $2.5 \pm 1.7$ & $2.7 \pm 1.9$ & $2.4 \pm 1.6$ & $2.5 \pm 1.8$ & $1.9 \pm 1.7$ \\
\hline Medical Expenditure ${ }^{1}$ & $8.51 \pm 9.87$ & $21.14 \pm 77.49$ & $18.88 \pm 26.72$ & $26.54 \pm 44.56$ & $28.57 \pm 44.67$ \\
\hline
\end{tabular}

${ }^{1}$ Figure are quoted in USD. Where 1 USD $=$ JA $\$ 69.06$

for policies and research in the area of health. In this work, we found that 31 percent of those with NCSs indicate that they have at least good health status compare to 26.3 percent who have poor self-rated health status. A study by Bourne found that 4.9 percent of Jamaicans report poor health, and that 82.2 percent report at least good health status [22] compared to present findings which show that those with NCDs are experiencing substantially lowered health status, more likely to being in poor health compared to the general populace. In fact, no one who notes having a NCD report excellent self-rated health status compare to 37.0 percent of Jamaicans.

Physical health of those with NCDs is equally important as deaths to these conditions. Studies show that the mortality statistics, globally, for those with chronic conditions are astounding, particularly those in developing nations, and the poor health status of those who are alive is equally alarming. Although Tilluckdharry [17] did not provide evidence on the self-rated health status of people living with NCD, he suggested that "Many cardiovascular events are not fatal but many cause sufficient debiliation to seriously affect function ability - up to 20 percent of disability-adjusted life years (DALY) are due to cardiovasular diseases", which offers some basis for the interpretations of the present findings. In Jamaica, comparatively, 5.4 times more of those with NCDs indicate poor self-rated health compare to the general populace and none of the former report excellent health Hence, the notion that chronic conditions ís a 'silent killer' is supported by the overall current health status of those with these diseases. This work goes further to disaggregate certain health indicators of Jamaicans living with NCDs in order to provide a comprehensive understanding of how illness has eroded general health of the population.

The challenge for many people with NCD is that they experience more than one condition. It is difficult to deal with one chronc condition and this is even more problematic when one considers that rarely people with these diseases only experience one of the disease, making health management complex, expensive and frustrating for those with the condition. In 2000, a Caribbean scholar and nutritionist indicate that 50 percent of those with hypertension have diabetes [5], which reinforces the point that there is comorbidities among those with chronic conditions. This again is supported with another study that was conducted in 2008 which finds that $60 \%$ of those with hypertension had at least two NCDs. Such information explain the perspective of a medical doctor (Professor Morrison) who opines that diabetes and hypertension as the twin problem in the Caribbean [6]. The current work is updating the figures of Callender and extending the discourse to other chronic diseases [5]. We find that 90.2 percent of those who indicate having hypertension have diabetes; 71.4 percent of those with diabetes have hypertension; 87.1 percent of those who report having arthritis have hypertension and 68.2 percent of those who have other chronic conditions have hypertension. Clearly, there is an increase in the morbidity rate reported by Callender in 2000 [5], and the perspective outlined by Morrison is correct and extends to other NCDs [6]. Self- 
Table 6: Binary Logistic Regression: Variables illustrate potential good health status.

\begin{tabular}{|c|c|c|c|c|c|c|c|}
\hline \multirow{2}{*}{ Characteristic } & \multirow{2}{*}{ B } & \multirow{2}{*}{ S.E. } & \multirow{2}{*}{ Wald } & \multirow{2}{*}{$\boldsymbol{P}$} & \multirow{2}{*}{ Odds ratio } & \multicolumn{2}{|c|}{ 95\% C.I. } \\
\hline & & & & & & Lower & Upper \\
\hline Age & -0.032 & 0.011 & 8.129 & 0.004 & 1.00 & 0.948 & 0.990 \\
\hline Married & -0.396 & 0.477 & 0.689 & 0.407 & 0.67 & 0.264 & 1.715 \\
\hline Single & -0.341 & 0.486 & 0.491 & 0.484 & 0.71 & 0.274 & 1.845 \\
\hline Other (divorced, etc) & & & & & 1.00 & & \\
\hline No Health Insurance (1=yes) & -0.372 & 0.344 & 1.168 & 0.280 & 0.69 & 0.351 & 1.353 \\
\hline Dummied Social Assistance & -0.406 & 0.600 & 0.458 & 0.498 & 0.67 & 0.205 & 2.160 \\
\hline Secondary & -0.616 & 0.991 & 0.387 & 0.534 & 0.54 & 0.077 & 3.764 \\
\hline Tertiary & 0.134 & 1.140 & 0.014 & 0.906 & 1.14 & 0.122 & 10.678 \\
\hline No formal education & & & & & 1.00 & & \\
\hline Gender (1=Male) & -0.171 & 0.353 & 0.233 & 0.629 & 0.84 & 0.422 & 1.686 \\
\hline Diabetes & -0.399 & 0.473 & 0.713 & 0.399 & 0.67 & 0.265 & 1.695 \\
\hline Hypertension & -0.046 & 0.362 & 0.016 & 0.899 & 0.96 & 0.469 & 1.943 \\
\hline Arthritis & 1.039 & 0.539 & 3.715 & 0.054 & 2.83 & 0.983 & 8.129 \\
\hline Other chronic conditions & & & & & 1.00 & & \\
\hline Middle class & -0.432 & 0.431 & 1.005 & 0.316 & 0.65 & 0.279 & 1.511 \\
\hline Upper class & 0.001 & 0.473 & 0.000 & 0.999 & 1.00 & 0.396 & 2.530 \\
\hline Poor & & & & & 1.00 & & \\
\hline lnLength of illness & -0.494 & 0.123 & 16.242 & $<0.0001$ & 0.61 & 0.480 & 0.776 \\
\hline InMedical Expenditure & -0.068 & 0.124 & 0.298 & 0.585 & 0.93 & 0.732 & 1.192 \\
\hline Crowding & 0.061 & 0.073 & 0.713 & 0.398 & 1.06 & 0.922 & 1.226 \\
\hline Income & 0.000 & 0.000 & 0.002 & 0.966 & 1.00 & 1.000 & 1.000 \\
\hline Constant & 2.600 & 1.249 & 4.333 & 0.037 & 13.46 & & \\
\hline
\end{tabular}

Model $\chi 2=51.55, \mathrm{P}<0.0001$

$-2 \mathrm{LL}=299.92$

$\mathrm{R}^{2}=0.224$

reported prevalence of comorbidities in South Africa was 22.5\% [19], which is far less than than in Jamaica and this excludes those who are not cognizant of their NCDs status. Wilks and colleagues' found that 49.3 percent of Jamaicans aged 15 to 74 years were unaware of having hypertension. There were 23.9 percent who were not cognizant of the fact that they have diabetes along with 57.2 percent being at least satisfied with life. Within the context of the health status of those with NCDs as well as the high rate of comorbidities, dissatisfaction with life among these people must be far greater than for those without cardiovascular diseases [7].

The greater degree of dissatisfaction with life among those with NCDs can be expounded upon here as many studies have found that income is positively correlated with good health status [25-27], and this is not the case for those with chronic diseases. In fact, Marmot [25] opines that income is critical to good health status; but this work debunks this theory as we find that income is not statistically associated with good health status of those with chronic conditions. The reality is, 42.5 percent those with NCDs in Jamaica are wealthy, with 21.2 percent being among the wealthiest $20 \%$, which denotes that they have the economic resources to manage their health conditions; yet none of those with these diseases indicate excellent health status and only 30.6 percent report good health status. There is no doubt that money opens access to better health care and medication; but it cannot buy better health as evidenced among those with chronic illnesses. The rationale for such a perspective is embedded in the finding that shows no statistical correlation between medical expenditure and good health status, and health insurance coverage and good health as well as income and good health. This study shows that there is no statistical correlation between income quintile and health status of those with chronic conditions, suggesting that even with money those in the wealthiest twenty (20\%) percent health status is no different than for those in poorest twenty $(20 \%)$ percent. Instead money (or access to economic resource) opens health-care seeking behavior and health insurance coverage of those who are wealthy among have chronic illness; but does not influence their health status.

We can further the discourse of money buying health, by examining deaths of those with NCDs. The World Health Organization purports that 80 percent of deaths in developing nations are as a result of chronic conditions [1], which is concurred by other studies [14-17] and even statistics on Jamaicans show that ten leading causes of deaths are chronic diseases such as diabetes, hypertension, arthritis, neoplasms, ischaemic heart diseases and other heart conditions [28]. From the WHO's statistics as well as those of other studies and statistics on chronic diseases in Jamaica, NCDs are equally spread across the income quintiles. A further examination of particular chronic diseases by income quintile offers an insight in the impartiality of these illness affects the socio-economic groups within the society. Nevertheless, there is a substantial rise in percentages of the illness by income quintile as in 1991, Theodore et al [29] found that 8.2 percent of those with hypertension are in the poorest $20 \%$ compare to 10.0 percent of those in the wealthiest twenty (20\%) 
percent. The present work, however, reveals that 22.8 percent of hypertensive are in the poorest $20 \%$ compare to 18.4 percent of the wealthiest twenty (20\%) percent. Furthermore, in 1991, 1.8 percent of diabetes are in the poorest $20 \%$ compare to 3.0 percent in the wealthiest twenty (20\%) percent. This work reveals that 17.1 percent of diabetics are in the poorest $20 \%$ compare to 26.8 percent in the wealthiest twenty (20\%) percent. Those findings show that there is an exponential rise in hypertension among those in the wealthiest $20 \%$ as well as diabetes, which means that having money cannot retard or alleviate chronic conditions as this would have been done by those in the wealthiest income quintile. The findings of the current work supports a study done in South African that finds that the wealthy had a greater prevalence of NCDs compared to the poor [19]. In fact the lifestyle of those with money is destroying their health status, and not having money is equally detrimental to health status. The WHO reports that sixty $(60 \%)$ percent of global mortality are caused by chronic illness and $80 \%$ of chronic illnesses were in low and middle income countries, and the present study concretizes chronic conditions do not respect economic status, and that the poor are implicated the same way as the affluent people in the developing world.

The faces of those with chronic illness are important in a discussion of health and diseases. There is gender and age position for caridiovasular diseases that are well recorded in the literature $[9,15,19,29]$ and this work concurs other health studies. The World Bank finds that 70 percent of mortality among females are accounted for by NCDs as well as that leading causes of deaths among people 45+ years old are chronic conditions [30]. Statistics on mortality in Jamaica reveal that this is a feminine phenomenon at older ages and at younger ages it is a male issue [28], which is endorsed by a study on mortality at older ages by Bourne, McGrowder and Crawford [31]. There is no study to verify the work of WHO on the percentage of mortality among females owing to chronic conditions; but morbidity of those conditions could be used to examine that 70 percent. Although this work is not on mortality, there is a clear gendered aspect to chronic diseases occuring in Jamaica as we find that 65.3 percent of those with NCDs are females, 46.4 percent are 60+ years old, 65.7 percent are at least 45 years old and 82.3 percent are older than 31 years old. Jamaica is not atypical as it relates to illnesses being gender and age specific. Jamaica like Colombia experience a similar gender-age health reality [32], which is also the case in Peru [33], South Africa [19], and Mexico [34]. However, what emerges from this work is the $9.2 \%$ of children less than 15 years old who have NCDs.

Those with NCDs are not only elderly and female as is revealed in the literature; they are also children, rural residents, lowly educated (no formal education, 88.7\%), and single people $(42.7 \%)$. All those findings provide a context that allow us to modify the poverty-ill discourse which is well established in the literature. According to Alleyne [35] "The impact of poverty on health is still evident today and in every country it will be the poor who are the most disadvantaged, both in terms of health outcomes and in access to factors that make for good health" [35], which are not supported by the current findings. In fact,
NCDs are more middle-class to wealth phenomenon and this is a modification of the poverty-illness theory. Outside of those realities, there is a newness in terms of children having NCDs such diabetes, neoplasms and heart diseases $(9.2 \%$ of those which NCDs are people less than 15 years old). The aforementioned 9.2\% may not seem alarming, but a study by Bourne [36], over a five-year period, discovered that some of the NCDs in children have increased by over 300 percent. There is no doubt, therefore, that NCDs are age and gender specific. There is a profound health effect of diseases on children, especially infant, as their life will be lived somewhat different from other children and then there is the negative psychology of this on them.

Clearly there is a health psychology that is embedded in the rise of children with NCDs and a comprehensive examination of this matter must still to be done. According to Bourne [24] the prevalence rate of diabetes in Jamaican children has increased by over 100 percent between 1999 and 2008, which opens a discussion of the birth defects instead of lifestyle practices. The present work reveals that $1 / 50$ diabetics in Jamaica are less than 15 years and this is explained by Morrison who postulates that "Diabetes mellitus (DM) is a leading cause of birth defects, perinatal complications, and the death of both mother and child" [16], which highlights a rationale for public education programmes on maternity issues, mortality and how pregnant mothers' sedentary lifestyles can influence the health of their unborn child/ren. The rationale that expands the call for a public education programme on the matter of NCDs specifically geared toward pregnant mothers and females in child bearing ages is based on what Unwin and Alberti believe that "Up to $80 \%$ of all cases of cardiovascular disease or type- 2 diabetes and $40 \%$ of all cases of cancer, for example, are probably preventable based on current knowledge" [37].

The issue of ignorance is resulting in children being born with NCDs primarily because of the sedentary lifestyle of their mothers as mothers in developing countries continue to expose their unborn child/ren to high risk factors that are resulting in the number of children being born with chronic health conditions [38]. Chronic non-communicable diseases have reached an epidemic proportion in Jamaica that is similar to the case in Africa $[39,40]$ and many nations $[1,41-46]$. When one takes into consideration multimordidities that have a higher prevalence rates among females and aged people in the world [41-45], which is no different in Jamaica as well as the wider Caribbean [46-48] and other nations $[49,50]$; then, there is the societal and national burden of NCDs. Diabetes mellitus is not the only challenge faced by the population as McCarthy [8] feels that between $30 \%$ to $60 \%$ of diabetics also suffer from depression which is a psychiatric illness. When combined with other morbidities such as hypertension, arthritis, and other NCDs, the psychosocial challenges as well as health impacts are profound and must be address with some sense of urgency. The rise in chronic diseases is more than a individual burden, they are now an epidemic with national, a potential global significance that have socio-economic and mortality cost. There is a need to urgently implement measures that must begin at the primary educational level in 
order to address the health epidemic happening in the developing world, especially the English-speaking Caribbean nations.

The missing element in the current discourse is lifestyle practices of people, which account for the epidemiological transition occuring in the world. Brannon and Feist [51] explained that "In the early 1900s, people's diseases were largely the result of contact with impure drinking water, contaminated foods, or sick people." They also say that "During the last few years of the $20^{\text {th }}$ century, deaths from chronic diseases - those related to unhealthy lifestyles and behavior...", which is equally the case in the developing nations as well as the Caribbean. What better ways to express the unhealthy lifestyle practices of people than by using alcohol consumption, marijuana usage, physical activity (or inactivity) and cigarette smoking.

A national probability study of Jamaicans aged 15 to 74 years reveal that in $2000,62 \%$ of respondents indicate that they are current users of alcohol and this increased to $74.5 \%$ in 2008 [25]. Current alcohol usage in 2008 is even greater among those 1) 1524 years old, $77.5 \%$; 2) 25-34 years old, $83.2 \%$; and 35-44 years old, $80.0 \%$ [7]. Alcohol consumption among the elderly, 65-74 years old, is $48 \%$, which highlights a pervasive unhealthy lifestyle practice among Jamaicans. Comparatively, $13.5 \%$ of Jamaicans are current users of marijuana (in 2008) and 14.5\% cigarette users [7]. Outside of cigarette smoking, marijuana usage among Jamaicans is $32.5 \%$ - males, $48.1 \%$ and females, $17.6 \%$ - which shows another culturalized and gendered perspective to the marijuana consumption. Coupled with the aforementioned result is the inactivity of Jamaicans, with only $33 \%$ of respondents indicating that they are high-physically active (exercise) compared to $45.3 \%$ who are low-physically active [25]. It should come as no surprise, therefore, that $51.7 \%$ of Jamaicans are either overweight or obese, twenty-five (25.3\%) percent [7] because of physical inactivity and caloric intakes that are mostly fats. Those issues provide a rationale for the high prevalence and incidence rates of NCDs in Jamaica, which is equally the same across the Caribbean region, and can be used to explain the reason for discounting life expectancy of people for time lived with illnesses. The reality is, it is empirically established that cigarette smoking, alcohol abuse, unhealthy eating practices, stress and sedentary lifestyles are linked with NCDs [52,53] and that modernity has offered little solace to changing poor and unhealthy practices of peoples despite having information, technology, advanced regulatory frameworks and more economic resources.

The discourse of the public health challenge of noncommunicable diseases (NCDs) can be addressed with policy development and implementation. Ferguson et al. [54] state that Jamaica implemented various programmes, in the late 1990s, to address NCDs and these initiatives were extended to the wider Caribbean region. In 2007, Caribbean heads of governments convened a meeting specifically geared towards NCDs' management and control. One year later, the Pan American Health Organization (PAHO) along with 28 key groups drafted a document emanating from the summit that would address NCDs reduction and organization [4]. Prior to 2007, there was a conference in Nassau, in 2001, that sought to implement a regional plan of action towards preventing and controlling NCDs [4]. Nevertheless, the only evidence the region had to show for these programmes are higher prevalence of NCDS as well as increased unhealthy lifestyle practices. One Caribbean psychiatrist, Wendel Abel [55], argues that the use of marijuana, which is the most widely used illicit drug in Jamaica, and despite its association with mental health disorders, continues to be demanded and used by more people each year.

Illicit drug usage, cigarette smoking, poor nutrition, low physical exercise, and cultural practices continue to erode the efforts of policy makers and health care practitioners (i.e., professionals). By simply arguing that policies that have been implemented to correct the poor behavioral practices of the population are enough, would be myopic and distant from contemporary realism. Abel [55] aptly summarizes the ineffectiveness of legislative framework and policies to curb human behaviour in Jamaica, when he writes that "It is clear that legislation, as a strategy to shape attitude and discourage use, has not taken root and will not work within our sociocultural context where cannabis culture has proliferated and is widely accepted". Such a perspective can be applied to explain cultural practices like, 1) high consumption of fatty foods such as pork, 2) sweets including highly sweetened beverages, and 3) alcohol consumption, and the difficulty that public health and other health professionals as well as policies makers have reducing and eliminating theunhealthy behaviors, even in the face of legislation. A large percentage of people with NCDs and those dying from those conditions speaks to the debunking the claim of merely drafting policies to address behaviors of people is not enough. A more robust multifaceted approach must be taken in order to more effectively understand the population's culture, which is the key to determing the decisions and practices of this group.

Cultural practices are historical milestones that are revered by people, difficult to change and form an invincible barrier against effective policy implementation that is geared towards behavioral modifications [56]. There is no doubt that the human behavior is multi-faceted as well as complex, and modifications are even more challenging because cultural practices are rooted into the population's sub-consciousness. A possible rationale for this complexity in human behavior modifications is the fact that people are not rational being; they are products of their psychosocial milieu and biological composition, and are constantly changing and redefining themselves. This is aptly captured in a study on factors, which explain behavioral modications of people. Bourne and colleagues [56] found that health demands for Jamaicans is comprised of many psychosocial factors including severity of illness and typology of health condition, with health promotion being the reciprocated health demand function. Hence, Bourne et al's health demand and health promotion model provides not only an empirical understanding of complexities of human health behavior modifications; but, it also opens a window to challenge human behavior change without simultaneously changing many psychosocial conditions of people. According to Glanz et al. [57] "While it is reasonable to assume that a theory such as HBM [Health Belief Model] is applicable to different cultures, it is also 
important to realize that constructs may have to be adapted to make them more relevant to the target culture." This further highlights the complexities of human behaviour and argues for a multifaceted approach in human behavior modification. Clearly, embedded in the current findings are continued challenges of health policy planners including behavioral scientists to explore a change in the lifestyle of Jamaicans so much that there can be an effective and sustainable reduction in NCDs.

With the increasing prevalence, incidence rates and burden of NCDs in developing nations [58-66], the challenges of human behavior modifications are not limited to Jamaica; instead this is prevalent on a global scale. The complexity of addressing NCDs in developing countries has even been described as "A Race Against Time" [60] and this is rightfully so; but three critical elements that have been omitted in the discourse are the difficulties in changing concretized cultural practices and the lack of disposable income, as well as poor lifestyle choices. Indeed, there must be a 'Race Against Time' [60], cultural practices, and money as NCD even more so an English-speaking Caribbean phenomenon as while NCDs are twice that of communicable diseases globally [1], for 2003-2005, deaths by way of NCDs were 250 per 100,000 in the English-speaking Caribbean compared to 70 per 100,000 for communicable diseases [67]. The facts presented in this study go further to justify urgent multi-sectoral policy implementation initiatives including concretized cultural practices initiatives and money-health management, especially in an English-speaking country such as Jamaica. 'A Race Against Time' [60] is long gone in developing nation as it relates to addressing the NCDs epidemic; the new reality is a 'Race Against Catastrophe' and further inactions will only exasperate the situation.

There is no truth to the notions that money buys health, and that illness is a poor people phenomenon. Those two theories are laid to rest as money does not influence good health status of those with NCD. With the assumption of this old perspective and theorizing that is set aside is poverty and illness, as we find that non-communicable diseases are higher among the wealthy than the poor, which opens an insight into the risky lifestyle behaviourl practices of those with economic resources. In fact, their unhealthy lifestyle accounts for a greater prevalence of noncommunicable diseases, and their wealth will have little value in reversing years of poor health decisions. Outside of the incomehealth discourse, there is evidence that children are susceptible to developing NCDs, which would be related to 1) genetic compositions, 2) poor practices of females during pregnancies and 3) the ignorance of couples in not knowing that their actions (or inactions) affect the unborn child. A study by a team of research supports early life conditions including in uteroa, poor nutrition in early infancy and early infectious diseases lead to NCDs in later adulthood [68]. In an article published by Caribbean Food and Nutrition Institute, the prevalence rate of diabetes mellitus affecting Jamaicans is higher than in North American and "many European countries" [5], and within the context that there is comorbidity instead of a single morbidity, this speaks to the lowered health of many people in Jamaica compared to those in North America and Europe. What contributes to this high prevalence rate of NCDs in Jamaica is lifestyle practices during adolescents, which is captured by Wilks and colleagues [7]. They find that only $63 \%$ of Jamaicans ages $15-24$ years had normal body weight; $20.4 \%$ experience depression; $4 \%$ with high cholesterol; $32 \%$ are pre-hypertensive; $76 \%$ current use alcohol; $13 \%$ and $10 \%$ are current marijuana and cigeratte users, respectively; $22 \%$ and $12 \%$ of females and males were lowly physically active, respectively [7]. Another study on Jamaicans highlighting risk factors among those with hypertension or prehypertension find that $63.5 \%$ of women are either overweight or obese compared to $27.6 \%$ of women, and that men are more likely to be current smokers $(34.9 \%)$ compared to $14.6 \%$ of women [53]. Such findings speak to the lifestyle behavioural practices even among those are experiencing NCDs and this offers an insight into difficulty of setting aside poor practices.

\section{Conclusion}

The information gleaned from this study are enlightening and open windows into comorbidities, sedentary lifestyles, socialization and poor health status of many people living with chronic diseases. It is also a crucial platform in justifying reasons for launching new policy programmes, particularly health education and nutritional restrictions on foods and beverages. These initiatives and programmes must include individual and societal risk factors - including stress and obesity - age and gendered programmes, socialization and diet, environmental risk factors, testing for gestational diabetes in all pregnant females, expenditure on the prevention and control of NCDs as well as regulations on foods and beverages. Outside of the previously discussed matters, an issue that is unexplored in health literature in the Caribbean region is the prevalence of stunted children and its contribution to later hypertension, obesity, diabetes and other chronic diseases. The NCDs epidemic is such that research must explore all probable areas in order to determine causal explanations in an effort to effectively design policies and initiatives that will address the epidemic; hence, we recommend national cross-sectional and longitudinal studies on growth during infancy and early children and its influence on later chronic non-communicable diseases in the region.

\section{References}

1. World Health Organization (2005) Preventing chronic diseases: a vital investment. WHO, Geneva:

2. Van Agt HME, Stronks K, Mackenbach JP (2000) Chronic illness and poverty in the Netherlands. Eur J of Public Health 10: 197-200.

3. Bourne PA (2009) Impact of poverty, not seeking medical care, unemployment, inflation, self-reported illness, health insurance on mortality in Jamaica. North Am J Med Sci 1: 99-109.

4. Hospedales CJ, Samuels TA, Cummings R, Gollop G, Greene E (2011) Raising the priority of chronic noncommunicable diseases in the Caribbean. Rev Panam Salud Publica 30(4): 393-400.

5. Callender J (2000) Lifestyle management in the hypertensive diabetic. Cajanus 33: 67-70.

6. Morrison E (2000) Diabetes and hypertension: Twin trouble. Cajanus 33: 61-63.

7. Wilks R, Younger N, Tulloch-Reid M, McFarlane S, Francis D (2008) Jamaica health and lifestyle survey 2007-8. Technical report. 
Epidemiology Research Unit, Tropical Medicine Research Institute, University of the West Indies, Mona.

8. McCarthy FM (2000) Diagnosing and treating psychological problems in patients with diabetes and hypertension. Cajanus 33: 77-83.

9. Bourne PA, McGrowder DA (2009) Health status of patients with selfreported chronic diseases in Jamaica. N Am J Med Sci 1(7): 356-364.

10. Bourne PA, McGrowder DA (2010) Socio-demographic determinants of health status of elderly with self-reported diagnosed chronic medical conditions in Jamaica. Health 2(2): 101-111.

11. Bourne PA (2010) Disparities in self-rated health, health care utilization, illness, chronic illness and other socioeconomic characteristics of the insured and the uninsured. Journal of Clinical and Diagnostic Research 4: 2804-2816.

12. Bourne PA (2013) Chronic diseases, self-rated health status, health care utilization and health insurance status of males in a caribbean nation. J Behav Health 2(1): 66-78.

13. Bourne PA, Charles CAD (2011) Hypertensive and modeling their social determinants of self-rated health status in a middle-income developing nation. Journal of Clinical and Diagnostic Research Journal of Clinical and Diagnostic Research 5(1): 01-08.

14. Wilks R (2005) Hypertension: Burden and risk factors. In Owen Morgan (Ed.) Health issues in the Caribbean. Ian Randle Publishers, Kingston, pp. 98-114.

15. Hagley KE (2005) Diabetes mellitus. In Owen Morgan (Ed.) Health issues in the Caribbean. Ian Randle Publishers, Kingston, pp. 115-121.

16. Morrison E St A (2005) Diabetes mellitus: the ravages (Abridged) In Owen Morgan (Ed.) Health issues in the Caribbean. Ian Randle Publishers, Kingston, pp. 122-123.

17. Tilluckdharry R (2005) Coronary artery disease: The rise to prominence (abridged). In Owen Morgan (Ed.) Health issues in the Caribbean. Ian Randle Publishers, Kingston, pp. 124-127.

18. World Health Organization (2000) WHO issues new healthy life expectancy rankings: Japan number one in new 'Healthy Life' system. Washington D.C. \& Geneva.

19. Phaswana-Mafuya N, Peltzer K, Chirinda W, Musekiwa A, Kose Z, et al. (2013) Self-reported prevalence of chronic non-communicable diseases and associated factors among older adults in South Africa. Glob Health Action 6: 20936

20. Planning Institute of Jamaica (PIOJ) (1990-2010) Statistical institute of Jamaica (STATIN). Jamaica survey of living conditions, 1989-2009. Kingston, Jamaica.

21. Bourne PA (2009) Good health status of older and oldest elderly in Jamaica: are there differences between rural and urban areas? Open Geriatric Medicine Journal 2: 18-27.

22. Bourne PA (2013) Health, social inequalities and food expenditure the implications of the economic and financial crises. J Behav Health 2(2): 173-188.

23. Bourne PA (2010) A comparative analysis of the health status of men aged 60-72 years and men aged 73+ years in Jamaica: are there differences across municipalities? Afr J Prm Health Care Fam Med 2(1): 8.

24. Thomas C (2005) Coronary artery disease: the reasons. In Owen Morgan (Ed.) Health issues in the Caribbean. Ian Randle Publishers, Kingston, pp. 128-130.

25. Marmot M (2002) The influence of Income on Health: Views of an
Epidemiologist. Health Affairs 21: 31-46.

26.Grossman M (1972) The demand for health- a theoretical and empirical investigation. National Bureau of Economic Research, New York.

27. Smith JP, Kington R (1997) Demographic and economic correlates of health in old age. Demography 34(1): 159-170.

28. Statistical Institute of Jamaica (1971- 2013) Demographic statistics, 1970-2012. Statistical Insitute of Jamaica, Kingston.

29. Theodore K, Lafoucade A, Stoddard D, Thomas W, Yearwood A (2001) Health stystem inequalities and poverty in Jamaica. In: Pan American Health Organization. Investment in health: social and economic returns, Scientific and technical publication, No. 582. Washington DC, 189-206.

30. World Bank (1996) Jamaica- achieving macro-stability and removing constraints on growth: country economic memorandum. World Bank, Washingston DC.

31. Bourne PA, McGrowder DA, Crawford TV (2009) Decomposing mortality rates and examining health status of the elderly in Jamaica. The Open Geriatric Medicine Journal 2: 34-44.

32. Ribero R, Nunez J (2001) Productivity of household investment in health: the case of Colombia. In: Pan American Health Organization. Investment in health: social and economic returns, Scientific and technical publication, No. 582. Washington DC, p. 35-62.

33. Cortez R (2001) Health and productivity in Peru: an empirical analysis by gender and region. In: Pan American Health Organization. Investment in health: social and economic returns, Scientific and technical publication, No. 582. Washington DC, p. 87-115.

34. Mayer D, Mora H, Cermeno R, Barona AB, Duryeau S (2001) Health, growth, and income distribution in Latin America and the Caribbean: a study of determinants and regional and local behaviour. In: Pan American Health Organization. Investment in health: Social and economic returns, Scientific and technical publication, No. 582. Washington DC, p. 3-34.

35. Alleyne GAO (2001) Equity and health. In: Pan American Health Organization. Equity and health, Occasional publication, No. 8. Washington DC, p. 3-11.

36. Bourne PA (2012) Health of children in Jamaica: the new health realities. Indian J Med Sci 66(7\&8): 175-188.

37. Unwin N, Alberti KG (2006) Chronic non-communicable diseases. Ann Trop Med Parasitol 100: 455-464.

38. Arora A, Khan QA, Arora V, Setia N, Khan BV (2013) Growing cardiovascular and metabolic diseases in the developing countries: is there a role for small dense LDL particles as an inclusion criteria for individuals at risk for the metabolic syndrome? J Community Med Health Educ 3: 243.

39. Omoleke SA (2013) Chronic non-communicable disease as a new epidemic in Africa: focus on the Gambia. Pan Afr Med J 14: 87.

40. Mayosi BM, Flisher AJ, Lalloo UG, Sitas F, Tollman SM, et al. (2009) The burden of noncommunicable diseases in South Africa. Lancet 374: 934-947.

41. Khanam MA, Streatfield PK, Kabir ZN, Qiu C, Cornelius C, et al. (2011) Prevalence and patterns of multimorbidity among elderly people in rural Bangladesh: a cross-sectional study. J Health Popul Nutr 29: 406-414.

42. Freid VM, Bernstein AB, Bush MA (2012) Multiple chronic conditions 
among adults aged 45 and over: trends over the past 10 years. NCHS data brief, Hyattsville, MD.

43. Kirchberger I, Meisinger C, Heier M, Zimmermann A-K, Thorand B, et al. (2012) Patterns of multimorbidity in the aged population. Results from the KORA-age study. PLoS One 7: e30556.

44. Marengoni A, Angleman S, Melis R, Mangialasche F, Karp A, et al. (2011) Aging with multimorbidity: a systematic review of the literature. Ageing Res Rev 10: 430-439.

45. World Health Organization (2011) Global status report on noncommunicable diseases 2010. Geneva: World Health Organization.

46. McCarthy FM (2000) Diagnosing and treating psychological problems in patients with diabetes and hypertension. Cajanus 33: 77-83.

47. Hennis AJ, Fraser HS, Jonnalagadda R, Fuller J, Chaturvedi N (2004) Explanations for the high risk of diabetes-related amputation in a Caribbean population of black African descent and potential for prevention. Diabetes Care 27(11): 2636-2641.

48. Soyibo AK, Roberts L, Barton EN (2011) Chronic kidney disease in the Caribbean. West Indian Med J 60 (4): 464-470.

49. Nielen MMJ, van Sijl AM, Peters MJL, Verheij RA, Schellevis FG et al. (2012) Cardiovascular disease prevalence in patients with inflammatory arthritis, diabetes mellitus and osteoarthritis: a crosssectional study in primary care. BMC Musculoskeletal Disorder 13: 150

50.Wan He, Mark Muenchrath, Paul Kowal (2012) Shades of gray: A cross-country study of health and well-being of the older populations in SAGE countries, 2007-2010. Census Bureau, Washington DC, U.S.

51. Brannon L, Feist J (2007) Health psychology: an introduction to behavior and health. ( $6^{\text {th }}$ edn), Thomson Higher Education, California.

52. Jones-Burton C, Seliger SL, Scherer RW, Mishra SI, Vessal G, et al (2007) Cigarette smoking and incident chronic kidney disease: A systematic review. Am J Nephrol 27: 342-351.

53. Ferguson TS, Younger N, Tulloch-Reid MK, Lawrence-Wright MB, Forrester TE, et al. (2010) Progression from prehypertension to hypertension in a jamaican cohort: incident hypertension and its predictors. West Indian Med J 59(5): 486-493.

54. Ferguson TS, Tulloch-Reid MK, Cunningham-Myrie CA, DavidsonSadler T, Copeland S, et al. (2011) Chronic disease in the Caribbean: strategies to respond to the public health challenge in the region. What can we learn from Jamaica's experience? West Indian Med J 60: 397-411.
55. Abel W (2004) Substance use: Health consequences. In Morgan 0 (Ed.) Health issues in the Caribbean. Ian Randle Publisher, Kingston 79-86.

56. Bourne PA, McGrowder DA, Holder-Nevins D (2010) Public health behaviour-change intervention model for jamaicans: charting the way forward in public health. Asian Journal of Medical Sciences 2: 56-61.

57.Glanz K, Rimer BK, Lewis FM (2002) Health behavior and health education: theory, research, and practice. ( $3^{\text {rd }}$ edn), John Wiley and Sons, CA.

58.Epping-Jordan JE, Galea G, Tukuitonga C, Beaglehole R (2005) Preventing chronic diseases: taking stepwise action. Lancet 366: 1667-1671.

59. World Health Organization. Cardiovascular diseases (CVDs) Fact Sheet No 317

60. Leeder S, Raymond S, Greenberg H, Liu H, Esson K (2004) A race against time. The challenge of cardiovascular disease in developing countries. The Centre for Global Health and Economic Development.

61.Thun MJ, DeLancey J0, Center MM, Jemal A, Ward EM (2010) The global burden of cancer: priorities for prevention. Carcinogenesis 31: $100-110$.

62. World Health Organization. Cancer Facts Sheet No 297. World Health Organization Website 2011.

63. Horton R (2005) The neglected epidemic of chronic disease. Lancet 366: 1514.

64. Reddy KS, Yusuf S (1998) Emerging epidemic of cardiovascular disease in developing countries. Circulation 97: 596-601.

65. King H, Aubert RE, Herman WH (1998) Global burden of diabetes, 1995-2025: prevalence, numerical estimates, and projections. Diabetes Care 21: 1414-1431.

66. Wild S, Roglic G, Green A, Sicree R, King H (2004) Global prevalence of diabetes: estimates for the year 2000 and projections for 2030 . Diabetes Care 27: 1047-1053.

67. Pan American Health Organization Caribbean Community Secretariat (2011) Stategic plan of action for the prevention and control of chronic non-communicable diseases for countries of the caribbean community 2011-2015. Caribbean Community (CARICOM).

68. McEniry M, Palloni A (2010) Early life exposures and the occurrence and timing of heart disease among the older adult Puerto Rican population. Demography 47: 23-43. 